\title{
Article \\ Structural Analysis of Interstratified Illite-Smectite by the Rietveld Method
}

\author{
Xiaoli Wang ${ }^{1,2}$ and Hejing Wang 1,2,*(D) \\ 1 School of Earth and Space Sciences, Peking University, Beijing 100871, China; xiaoli.wang@pku.edu.cn \\ 2 Key Laboratory of Orogenic Belt and Crustal Evolution, Ministry of Education, Beijing 100871, China \\ * Correspondence: hjwang@pku.edu.cn; Tel.: +86-10-62750764
}

Citation: Wang, X.; Wang, H. Structural Analysis of Interstratified Illite-Smectite by the Rietveld Method. Crystals 2021, 11, 244. https://doi.org/10.3390/ cryst11030244

Academic Editor: Helmut Cölfen

Received: 9 February 2021

Accepted: 24 February 2021

Published: 28 February 2021

Publisher's Note: MDPI stays neutral with regard to jurisdictional claims in published maps and institutional affiliations.

Copyright: (C) 2021 by the authors. Licensee MDPI, Basel, Switzerland. This article is an open access article distributed under the terms and conditions of the Creative Commons Attribution (CC BY) license (https:// creativecommons.org/licenses/by/ $4.0 /)$.

\begin{abstract}
Rietveld method is a powerful tool in obtaining structural information of clay minerals by using of X-ray diffraction (XRD) patterns. However, the interstratified illite-smectites (I-S) show various stacking defects preventing the direct application of this method. It was shown that the Rietveld method combined with a recursive structure-factor calculation can be used for describing the stacking disorder of I-S. In this study, a series of samples with different stacking sequences and different proportions of layer types were chosen to verify the applicability of Rietveld method in determination of structural parameters of I-S. The Rietveld refinements were carried out on powder samples and oriented specimens in air-dry (AD) and ethylene glycol (EG) state. The structural information obtained by X-ray fluorescence (XRF) and thermal analysis were used as an independent test of the reliability of the refinements. The refined and experimental results were compared systematically and the relationship between structural parameter was discussed. For powder and oriented specimens, the refined results of occupancies of potassium and iron and the proportion of illitic layers showed consistent results. The refined value of cis-vacant layers was in good agreement with the experimental data. The reliability of the refinements increased with increasing proportion of illitic layers.
\end{abstract}

Keywords: Rietveld refinement; X-ray diffraction; Illite-smectite; crystal structure; Stacking faults

\section{Introduction}

Interstratified Illite-smectite (I-S) is one of the most common interstratified clay minerals found in sedimentary rocks. I-S are 2:1 dioctahdedral phyllosilicates and composed of non-expandable layers of illite and expandable layers of smectite. The stacking sequences and the proportions of different layer types of I-S are important symbols for the diagenetic stage division and also an important basis for determination oil formation and oil generation zone in oil and gas exploration and development [1-3].

The stacking sequences of I-S can be described by the term "Reichweite (R)" [4]. The Reichweite of I-S is commonly in a range from 0 to 3 (R0, R1, R2 and R3) [5,6]. R0 means the illitic and smectitic interlayers are random interstratified or disordered. The Reichweite values $R=1,2$ or 3 mean that the stacking sequences of illitic and smectitic interlayers are periodic and the structure is ordered (for example, R1 means ISIS, R2 means IISIIS, R3 means IIISIIIS) [7]. The crystal structure of I-S or the stacking of illitic and smectitic interlayers can be described by the "McEwan crystallite" [6] or "fundamental particles" models [8]. The McEwan crystallite is considered as a sequence of nonexpendable illitic and expandable smectitic interlayers separated by 2:1 layers. Fundamental particles are defined by 2:1 layers: single 2:1 layer is considered as a smectite particle, and layers with fixed interlayer potassium are considered as illite particles (Figure 1). The fundamental particle model can be regarded as a stack of layers and without crystallographic continuity between interface. 


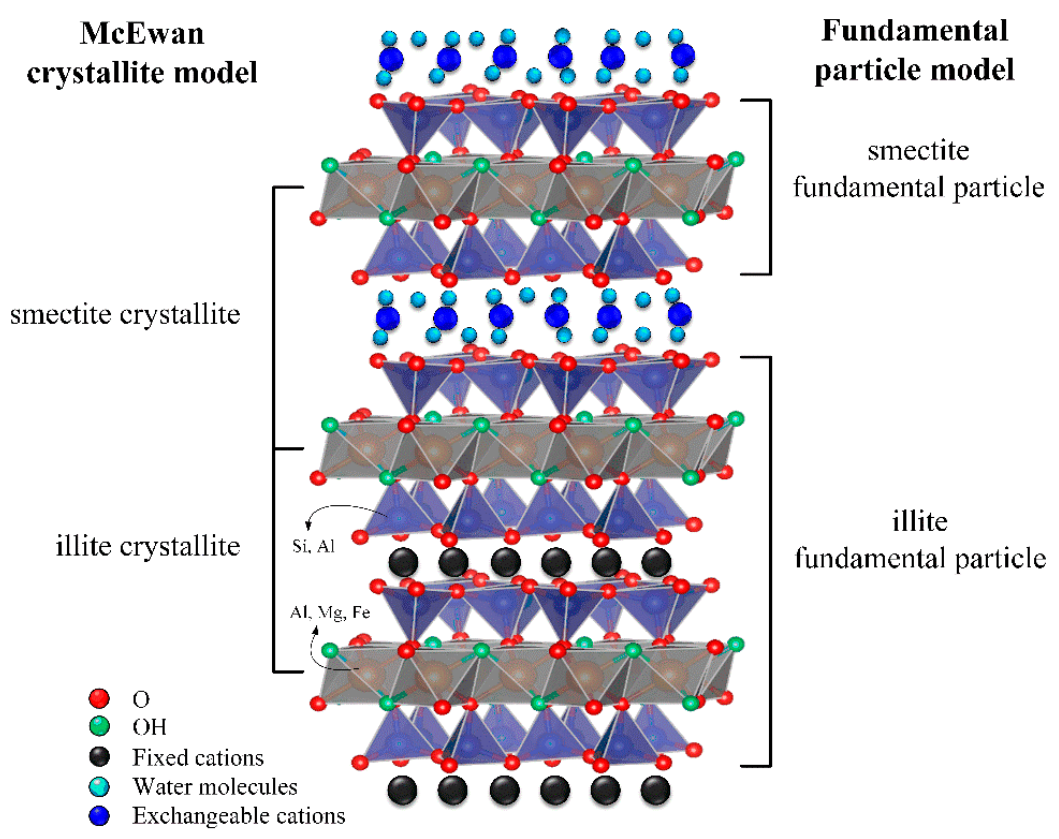

Figure 1. Structure models of I-S described by McEwan crystallite and fundamental particles.

As a phyllosilicate clay mineral, I-S exhibits various degrees of layer stacking disorder. Well defined rotation disorder: the adjacent 2:1 layers are rotated or translated to each other by $n \cdot 60^{\circ}$ or $n \cdot 120^{\circ}$ [9]. This kind of stacking normally occurs in illitic layers and with interlayer $K$ cation in the interlayer as the center of rotation. Turbostratic disorder [10]: the 2:1 layers are randomly rotated and shifted to each other in the $a-b$ plane. This extreme layer stacking disorder occurs only at the smectitic junctions in fundamental particles owing to the weak interactions between expandable (smectitic) layers [11]. These stacking defects will cause strong anisotropic peak broadenings called the non-Bragg diffraction effects $[7,12]$. Other structural defects recognized in I-S comes from the location of cation vacancies in the octahedral sheet. In general, 2:1 dioctahedral phyllosilicates show two configurations of octahedral sheet: cis-vacant $(c v)$ and trans-vacant (tv) [13-16]. The $c v$ and tv layers are randomly distributed in the illite particles of I-S interstratification. [17-19]. The study of $c v$ and $t v$ structure is important for understanding the mechanisms and dynamics during transformation of I-S [15,20-25].

X-ray powder diffraction (XRD) in combination with the Rietveld method [26,27] is a powerful method for characterization of clay minerals. However, these structure defects restrict the applicability of the conventional Rietveld method in the crystal structure analysis of I-S. [7,12]. Several programs containing automatic refinement routines could handle mineral mixtures and be used to model basal reflections, e.g., SYBILLA [28] and FITMOD [29]. However, the program that can model three-dimensional patterns of clay minerals with disordered mixed layers is limited. Reynolds [18,30] developed the program WILDFIRE for calculating the three-dimensional diffraction patterns of I-S with various disorder. The turbostratic disorder of smectite was modeled by a single layer approach [31] with the Rietveld program BGMN [32], and then it was successfully applied in quantitative phase analysis of smectites [33]. Later, the model was developed to refine the structural details of smectites, e.g., iron content, layer charge density and the proportions of $c v$ and tv layers $[34,35]$.

Ufer et al. [9,36] demonstrated that Rietveld method combined with a recursive structure-factor calculation was able to describe the stacking disorder of I-S. Nevertheless, only few trials of Rietveld refinement have been done on I-S by this approach. This study aims to verify the applicability of this approach in determination of structural parameters of I-S, such as the probability and proportion of layers; iron, calcium and potassium contents; the proportions of $c v$ and $t v$ layers. The Rietveld refinements are applied on oriented and 
powder samples. The structural parameters obtained by X-ray fluorescence (XRF) and thermal analysis are used as an independent test of the reliability of the refinements. The refined and experimental results are compared and the relationship between structural parameter is discussed. The refined structure parameters obtaining from XRD patterns of preferred oriented and powder specimens are compared systematically. The results are also compared with previous studies [9,36-38].

\section{Materials and Methods}

\subsection{Material Pretreatment}

A series of mixed layer illite-smectite (I-S) samples with different stacking sequences and proportions of layer types were selected for this study (Table 1). Three samples came from the Upper Silesian Basin (Poland): Ch4, 1M4 and 1Cz3 [9,37]. Sample Fuzz 6 was collected in Füzérradvány, Hungary [39] which is the same as sample F4 in the study of Ufer et al. $[9,36]$. Sample JCC-1 was collected in the Permian-Triassic boundary (PTB) sections, Guizhou Province, South China [38]. The reference sample ISCz-1 belongs to the Clay Minerals Society (CMS) source material repository.

Table 1. Samples information.

\begin{tabular}{|c|c|c|c|}
\hline Samples & Geological Conditions & Origin & References \\
\hline ISCz-1 & - & Slovakia & Clay Minerals Society (CMS) \\
\hline $\begin{array}{c}\text { Ch4 } \\
1 \mathrm{M} 4 \\
1 \mathrm{CZ3}\end{array}$ & Diagenetic & Upper Silesian Basin Poland & Środoń et al. [37] \\
\hline Fuzz 6 & Hydrothermal & Füzérradvány, Hungary & Viczián [39] \\
\hline JCC-1 & Diagenetic & PTB sections, Guizhou Province, South China & Hong et al. [38] \\
\hline
\end{tabular}

The bulk samples were lightly crushed in a mortar and then separated to $<2 \mu \mathrm{m}$ fraction by gravitational sedimentation. To get the enrichment of I-S and remove impurities, the particle-size separation of the $<0.2 \mu \mathrm{m}$ fraction was performed. The fraction $<0.2 \mu \mathrm{m}$ was obtained by centrifugation of the $<2 \mu \mathrm{m}$ suspension. Afterwards, the purified samples were saturated with $\mathrm{Ca}^{2+}$ using $1 \mathrm{~N} \mathrm{CaCl}_{2}$ solution and shaking overnight. The whole procedure repeated five times to ensure complete cation-exchange. The excess salt in the Ca-saturated dispersions was removed by dialysis method using deionized water several days until the electrical conductivity of the water outside the dialysis tubes is $\leq 1 \mu \mathrm{S} / \mathrm{cm}$. The suspension was washed with distilled water by centrifugation and the chloride free fractions were dried at $65{ }^{\circ} \mathrm{C}$. The dried samples were milled slightly in an agate mortar and collected.

\subsection{X-ray Fluorescence (XRF) Analysis}

The chemical compositions of samples were investigated with the X-ray fluorescence (XRF) analysis. The measurement was performed with a PANalytical Zetium spectrometer with a Rh anode. Due to the shortage of purified Ca-saturated I-S, only a small amount of sample was used in the measurement $(0.20 \mathrm{~g}$ to $0.25 \mathrm{~g})$. Samples were prepared by mixing with lithium tetraborate and lithium metaborate $(2: 1$, about $8.0 \mathrm{~g})$ as a flux material (CLAISSE) and melting into glass beads at $1050^{\circ} \mathrm{C}$ for $10 \mathrm{~min}$. The beads were analyzed by wavelength-dispersive XRF. The loss on ignition (LOI) was determined by heating the sample to $800^{\circ} \mathrm{C}$ for $120 \mathrm{~min}$. The result was used to calculate the structural formula of Ca-saturated I-S samples.

\subsection{Thermal Analysis}

The thermal analysis is considered to be an effective method to discriminate the structure of the octahedral sheet and determine the proportions of cis-vacant ( $c v)$ and transvacant $(t v)$ layers. The thermogravimetric (TG) and differential thermal analysis (DTA) 
measurements were performed using the device TA Instruments SDT Q600, with nitrogen as protective gas. About $12 \mathrm{mg}$ sample was used for each measurement with a heating rate of $10 \mathrm{~K} / \mathrm{min}$ in the temperature range of 25 to $1000^{\circ} \mathrm{C}$. The proportions of $c v$ and tv layers were obtained by fitting the derivative thermogravimetry (DTG) curves [21,40] in the range of 400 to $900{ }^{\circ} \mathrm{C}$ using the PeakFit program v4.12. The peaks area with the temperature below and above $600{ }^{\circ} \mathrm{C}$ correspond to the amount of $t v$ and $c v$ layers $[21,41]$.

\subsection{X-ray Diffraction (XRD) Data Collection}

The X-ray diffraction patterns of oriented and powder specimens were collected by an $X^{\prime}$ pert Pro MPD diffractometer with an $X^{\prime}$ Celerator detector, and using $\mathrm{Cu} \mathrm{K} \alpha$ radiation $(\lambda=0.154056 \mathrm{~nm}), 40 \mathrm{kV}$ and $40 \mathrm{~mA}$. The powder samples were prepared by the sideloading technique [19] to minimize the preferred orientation of the particles. The measured range of powder specimens was set from $2^{\circ}$ to $80^{\circ} 2 \theta$, with a step size of $0.03^{\circ} 2 \theta$ and $5 \mathrm{~s} / \mathrm{step}$. The oriented specimens were prepared by ultrasonically dispersing approximately $40 \mathrm{mg}$ samples in $2 \mathrm{~mL}$ of distilled water and sedimented the suspension onto a glass slide. Two different states of oriented samples were prepared: air-dried (AD) and ethylene glycol (EG) saturated. AD states formed when the suspension was dried at room temperature. The EG saturated states were prepared by saturating the air-dried oriented samples in ethylene glycol vapor in a desiccator at $60{ }^{\circ} \mathrm{C}$ overnight. The XRD patterns of oriented specimens in $\mathrm{AD}$ and EG state were recorded from $2^{\circ}$ to $40^{\circ} 2 \theta$ with a step size of $0.03^{\circ} 2 \theta$ and $5 \mathrm{~s}$ per step.

\subsection{Rietveld Refinement}

The BGMN program [32] was used for the Rietveld refinement. The structure models of oriented and random powder I-S specimens were described by Ufer et al. $[9,36]$, and used to determine the structural parameters, such as the probability and proportion of layers; iron, calcium and potassium contents and the proportions of $c v$ and $t v$ layers. The refined results of powder and oriented samples were compared systematically. During the refinement, the atomic positions in tetrahedral and octahedral sites were kept fixed. The occupancies of water molecules, EG molecules, interlayer cations ( $\mathrm{Ca}$ and $\mathrm{K}$ ), the proportion of $c v$ layers Pcv were refined. As a consequence, the proportion of $t v$ layers is calculated from the formula Ptv $=1-\mathrm{P} c v$. The background was fitted by a Lagrangian polynomial of 5 th degree. The main refined probability and proportion parameters are listed in Table 2.

Table 2. The main refined probability and proportion parameters.

\begin{tabular}{cc}
\hline & Refined Probability and Proportion Parameters \\
\hline$w \mathrm{I}$ & proportion of illitic layers \\
$\mathrm{p} 0$ & probability of adjacent layers without rotation \\
$\mathrm{P} 60 / 120$ & The ratio of $\mathrm{n} \cdot 60^{\circ}$ rotation to $\mathrm{n} \cdot 120^{\circ}$ rotation \\
$\mathrm{p} 60$ & probability of adjacent layers with $\mathrm{n} \cdot 60^{\circ}$ rotation \\
$\mathrm{p} 120$ & probability of adjacent layers with $\mathrm{n} \cdot 120^{\circ}$ rotation \\
$\mathrm{P} c v$ & probability of a cis-vacant layer \\
\hline
\end{tabular}

\section{Results and Discussion}

\subsection{Characterization of Samples}

Samples were characterized by XRF and thermal analysis. The results were used as an independent evaluation for the reliability of the refinement. Figure 2 shows the XRD patterns before and after purification of sample JCC-1. The intensities of reflections were enhanced significantly and impurities like quartz (Q) were removed effectively after purification. The XRF results after normalization are shown in Table 3. The chemical composition of Ca-saturated samples was calculated from the XRF analysis using the method described by Klein [42] based on one formula unit (FU) $\left[\mathrm{O}_{10}(\mathrm{OH})_{2}\right]$. Table 4 gives the structural formulae of the samples. The iron cation occupancy in octahedral sites 
was calculated using the octahedral iron content divided by the octahedral occupancy (Table 4). The occupancy of octahedral sites of samples was from 2.02 to 2.06 atoms per FU. The amount of $\mathrm{Fe}^{3+}$ was in the range from 0.02 to $0.17 \mathrm{~mol} / \mathrm{FU}$ (Table 4). The interlayer cations were mainly $\mathrm{Ca}^{2+}$ and $\mathrm{K}^{+}$. It was deduced that the exchange of cations with $\mathrm{Ca}^{2+}$ in the smectitic interlayers was complete. The fixed interlayer cation $\mathrm{K}^{+}$varies from 0.10 to $0.62 \mathrm{~mol} / \mathrm{FU}$, and the exchangeable cation $\mathrm{Ca}^{2+}$ varies from 0.05 to $0.19 \mathrm{~mol} / \mathrm{FU}$. The structural formulae of Ca-saturated samples are similar to the results of previous studies [9,36-38]. The deviation comes from different calculation methods.

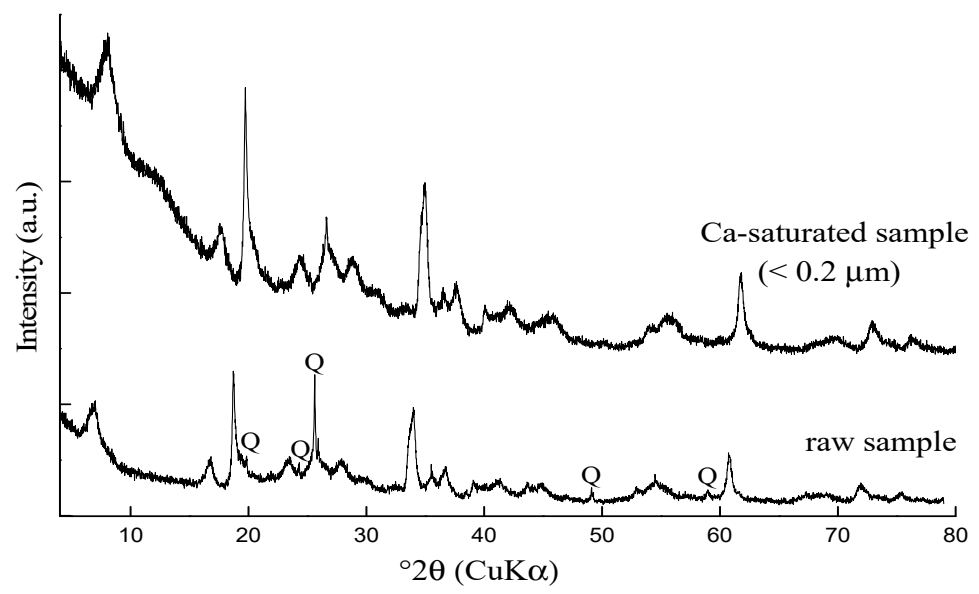

Figure 2. XRD patterns of sample JCC-1 before and after purification. Q-Quartz.

Table 3. Chemical compositions of samples obtained by XRF analysis $(<0.2 \mu \mathrm{m})$.

\begin{tabular}{cccccccccccccccc}
\hline \multirow{2}{*}{ Samples } & \multicolumn{10}{c}{ Oxides (\%) } \\
\cline { 2 - 13 } & $\mathbf{S i O}_{2}$ & $\mathbf{A l}_{\mathbf{2}} \mathbf{O}_{3}$ & $\mathbf{K}_{\mathbf{2}} \mathbf{O}$ & $\mathbf{C a O}$ & $\mathbf{M g O}$ & $\mathbf{F e}_{\mathbf{2}} \mathbf{O}_{3}$ & $\mathbf{Z n O}$ & $\mathbf{N i O}$ & $\mathbf{P}_{\mathbf{2}} \mathbf{O}_{5}$ & $\mathbf{T i O}_{2}$ & $\mathbf{Z r O}_{2}$ & $\mathbf{C u O}$ & LOI * & Sum before Normalization \\
\hline ISCz-1 & 47.10 & 25.53 & 4.47 & 0.88 & 2.15 & 1.65 & 0.04 & 0.00 & 0.00 & 0.00 & 0.00 & 0.00 & 18.18 & 97 \\
1M4 & 52.56 & 22.46 & 3.15 & 1.58 & 2.97 & 2.95 & 0.08 & 0.08 & 0.00 & 0.00 & 0.00 & 0.00 & 14.25 & 96.6 \\
Ch4 & 52.21 & 25.09 & 4.16 & 1.15 & 2.90 & 2.48 & 0.00 & 0.00 & 0.00 & 0.00 & 0.00 & 0.00 & 12.02 & 96.6 \\
Fuzz 6 & 50.41 & 30.08 & 7.22 & 0.72 & 2.47 & 0.42 & 0.00 & 0.00 & 0.00 & 0.00 & 0.00 & 0.00 & 8.67 & 96.4 \\
JCC-1 & 50.09 & 29.00 & 6.37 & 0.88 & 1.75 & 1.87 & 0.00 & 0.00 & 0.08 & 0.32 & 0.03 & 0.00 & 9.60 & 95.2 \\
ICz3 & 51.03 & 20.20 & 1.09 & 2.34 & 2.96 & 3.03 & 0.07 & 0.00 & 0.00 & 0.00 & 0.00 & 0.07 & 19.28 & 96.8 \\
\hline
\end{tabular}

${ }^{*}$ LOI: loss on ignition.

Table 4. Chemical formulae and octahedral information of Ca-saturated samples $(<0.2 \mu \mathrm{m})$.

\begin{tabular}{clcc}
\hline Samples & Chemical Formulae/FU & Occupancy of Octahedral Sites & Octahedral Iron Occupancy \\
\hline ISCz-1 & $\mathrm{K}_{0.42}^{+} \mathrm{Ca}_{0.07}^{2+}\left(\mathrm{Al}_{1.73} \mathrm{Fe}_{0.09}^{3+} \mathrm{Mg}_{0.24}\right)\left[\left(\mathrm{Si}_{3.50} \mathrm{Al}_{0.50}\right) \mathrm{O}_{10}(\mathrm{OH})_{2}\right]$ & 2.06 & 0.044 \\
$1 \mathrm{M} 4$ & $\mathrm{~K}_{0.28}^{+} \mathrm{Ca}_{0.12}^{2+}\left(\mathrm{Al}_{1.56} \mathrm{Fe}_{0.16}^{3+} \mathrm{Mg}_{0.31}\right)\left[\left(\mathrm{Si}_{3.70} \mathrm{Al}_{0.30}\right) \mathrm{O}_{10}(\mathrm{OH})_{2}\right]$ & 2.03 & 0.079 \\
$\mathrm{Ch} 4$ & $\mathrm{~K}_{0.37}^{+} \mathrm{Ca}_{0.08}^{2+}\left(\mathrm{Al}_{1.63} \mathrm{Fe}_{0.13}^{3+} \mathrm{Mg}_{0.30}\right)\left[\left(\mathrm{Si}_{3.59} \mathrm{Al}_{0.41}\right) \mathrm{O}_{10}(\mathrm{OH})_{2}\right]$ & 2.06 & 0.063 \\
Fuzz 6 & $\mathrm{~K}_{0.62}^{+} \mathrm{Ca}_{0.05}^{2+}\left(\mathrm{Al}_{1.78} \mathrm{Fe}_{0.02}^{3+} \mathrm{Mg}_{0.25}\right)\left[\left(\mathrm{Si}_{3.39} \mathrm{Al}_{0.61}\right) \mathrm{O}_{10}(\mathrm{OH})_{2}\right]$ & 2.05 & 0.010 \\
$\mathrm{JCC}-1$ & $\mathrm{~K}_{0.55}^{+} \mathrm{Ca}_{0.06}^{2+}\left(\mathrm{Al}_{1.74} \mathrm{Fe}_{0.10}^{3+} \mathrm{Mg}_{0.18}\right)\left[\left(\mathrm{Si}_{3.41} \mathrm{Al}_{0.59}\right) \mathrm{O}_{10}(\mathrm{OH})_{2}\right]$ & 2.02 & 0.050 \\
$\mathrm{ICz} 3$ & $\mathrm{~K}_{0.10}^{+} \mathrm{Ca}_{0.19}^{2+}\left(\mathrm{Al}_{1.53} \mathrm{Fe}_{0.17}^{3+} \mathrm{Mg}_{0.33}\right)\left[\left(\mathrm{Si}_{3.77} \mathrm{Al}_{0.23}\right) \mathrm{O}_{10}(\mathrm{OH})_{2}\right]$ & 2.03 & 0.084 \\
\hline
\end{tabular}

The proportions of cis- and trans-vacant layers of samples obtained by thermal analysis are presented in Table 5. The classification of $c v$ and $t v$ varieties was based on Wolters and Emmerich [41]. All samples were considered to contain both $c v$ and tv layers (Table 5). Samples ISCz-1, Ch4 and ICz3 were classified as $c v / t v$ varieties and they had the main dehydroxylation reaction around $700{ }^{\circ} \mathrm{C} ; 1 \mathrm{M} 4$, FUZZ6 and JCC-1 were classified as tv/cv varieties and they had the main dehydroxylation reaction near $650{ }^{\circ} \mathrm{C}$ with broad shoulder (Figure 3). A linear relationship was found between the octahedral $\mathrm{Fe}^{3+}$ and proportion of $c v$ and $t v$ configurations (Figure 4). The proportion of $c v$ layers decreased with increasing 
octahedral $\mathrm{Fe}^{3+}$ content (Figure 4). It agreed well with the previous studies [40,41,43]. The high iron content can reduce the dehydroxylation temperature due to the low bonding energy $[43,44]$.

Table 5. The proportions of trans- (tv) and cis-vacant $(c v)$ layers of samples and the classification.

\begin{tabular}{cccc}
\hline Samples & Proportion of $t v / \%$ & Proportion of $c v / \%$ & Classification \\
\hline ISCz-1 & 47.2 & 52.8 & $c v / t v$ \\
1M4 & 51.5 & 48.5 & $t v / c v$ \\
Ch4 & 48.6 & 51.4 & $c v / t v$ \\
Fuzz 6 & 54.9 & 45.1 & $t v / c v$ \\
JCC-1 & 68.8 & 31.2 & $t v / c v$ \\
ICz3 & 20.4 & 79.6 & $c v / t v$ \\
\hline
\end{tabular}

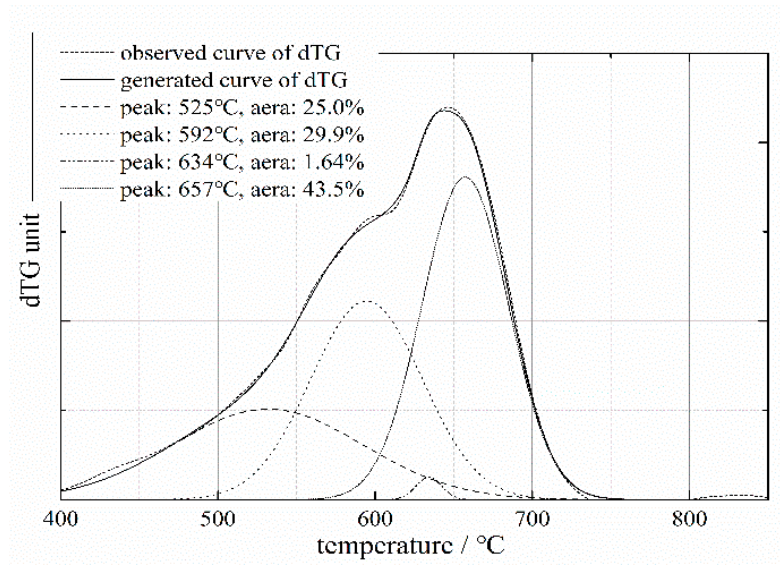

(a)

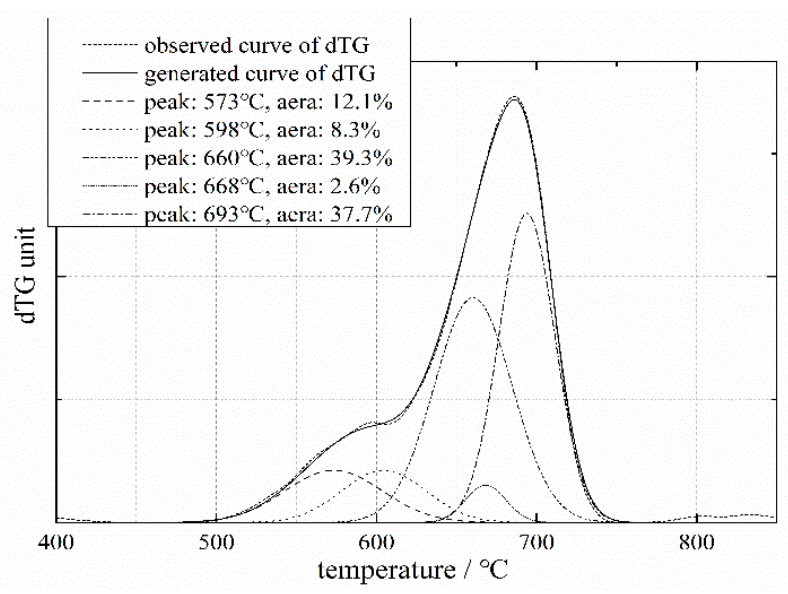

(b)

Figure 3. Examples of derivative thermogravimetry (dTG) curves of samples. (a) Sample Fuzz 6 with $45.1 \%$ of $c v$ layers; (b) Sample ICz3 with $79.6 \%$ of $c v$ layers.

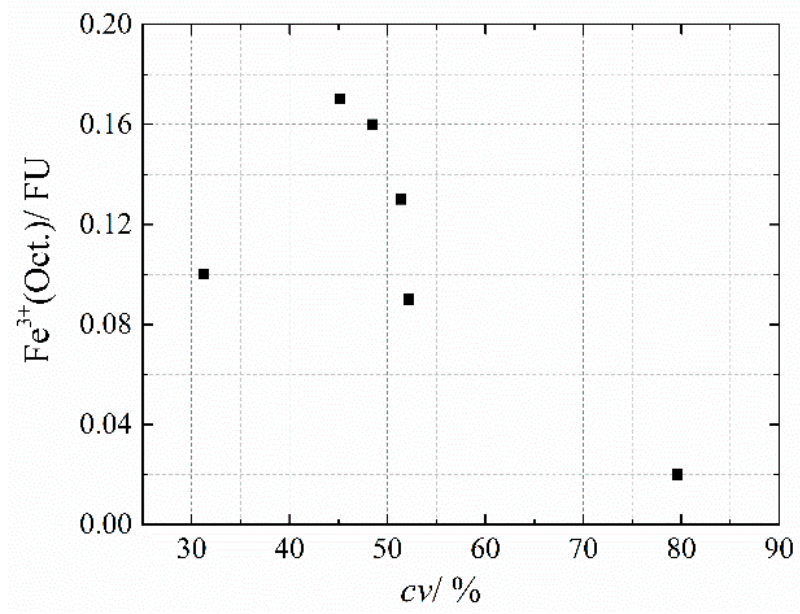

Figure 4. Relationship between the proportion of $c v$ layers and the octahedral iron content.

\subsection{Rietveld Refinement on the Oriented Specimens}

The weighted profile $R$ factor $R_{\mathrm{wp}}$ is used to assess the quality of refinement. The expected $R$ factor $R_{\text {exp }}$ represents the best possible value of $R_{\mathrm{wp}}$ can be reached. The values within three standard deviations $3 \sigma$ of the mean are used to evaluate the results. Structure models with different Reichweite types (R0, R1, R2 and R3) were chosen for each oriented sample in AD and EG state. The structure model led to the lowest $R_{\mathrm{wp}}$ was chosen for the further refinements of samples (Table 6). The selected model for each sample fit the XRD 
patterns suitably well. Both peak positions and the intensity distributions of all samples could be satisfactorily modelled (Figure 5). The $R_{\mathrm{wp}}$ values for samples in AD state range from approximately 7.06 to $10.75 \%$; for samples in EG state ranged from 8.20 to $10.47 \%$ (Table 7).

Table 6. Refinement results of oriented samples with different structure models.

\begin{tabular}{|c|c|c|c|c|c|c|c|c|c|c|c|c|}
\hline \multirow{3}{*}{ Models } & \multicolumn{12}{|c|}{$R_{\mathrm{wp}} / \%$} \\
\hline & \multicolumn{2}{|c|}{ ISCz-1 } & \multicolumn{2}{|c|}{ 1M4 } & \multicolumn{2}{|c|}{ Ch4 } & \multicolumn{2}{|c|}{ Fuzz 6} & \multicolumn{2}{|c|}{ JCC-1 } & \multicolumn{2}{|c|}{ ICz3 } \\
\hline & $\mathrm{AD}$ & EG & $\mathrm{AD}$ & EG & AD & EG & $\mathrm{AD}$ & EG & AD & EG & $\mathrm{AD}$ & EG \\
\hline R0 & 21.07 & 22.86 & 20.15 & 21.43 & 19.61 & 21.87 & 19.26 & 23.54 & 24.16 & 23.06 & 7.06 & 8.5 \\
\hline $\mathrm{R} 1$ & 8.85 & 9.69 & 7.66 & 8.2 & 8.67 & 10.47 & 13.89 & 20.16 & 16.29 & 20.74 & 8.54 & 9.07 \\
\hline $\mathrm{R} 2$ & 9.52 & 10.37 & 9.21 & 10.58 & 10.38 & 13.64 & 9.73 & 18.62 & 13.88 & 15.68 & 23.42 & 26.13 \\
\hline R3 & 19.06 & 23.49 & 19.64 & 23.97 & 21.96 & 22.09 & 7.25 & 8.54 & 10.75 & 8.95 & 25.56 & 27.2 \\
\hline
\end{tabular}


Figure 5. Rietveld refinements of oriented sample ISCz-1 and Fuzz6 in AD and EG state.

The proportion of illitic layers ( $w \mathrm{I})$ of samples ISCz-1, 1M4 and Ch4 in AD state refined with R1 model were $0.69,0.61$ and 0.71 . The samples Fuzz 6 and JCC- 1 in AD state refined with R3 model obtained the $w$ I values are 0.87 and 0.86 ; $\mathrm{AD}$ sample $1 \mathrm{Cz} 3$ refined with $\mathrm{R} 0$ model got the $w$ I values 0.22 . The refined $w$ I values for samples ISC $z-1,1 \mathrm{M} 4$ and $\mathrm{Ch} 4$ in EG state were 0.68, 0.52 and 0.64; for samples Fuzz 6 and JCC-1 in EG state were 0.85 and 0.86 ; for EG sample ICz3 was 0.13 (Table 7). The refined $w$ I values in AD state were slightly higher than EG state for samples containing low illitic layers, and the tendency became more obvious as the proportion of illite layer decreases (Figure 6). The refined $w \mathrm{I}$ of sample ISCz-1 in AD and EG state (0.69 and 0.68) were nearly identical with reference value 0.7 (CMS) and the values ( 0.715 and 0.683$)$ from Ufer et al. [9]. The refined $w \mathrm{I}$ values of sample Fuzz6 and JCC-1 in AD and EG state were consistent with the study of Ufer et al. [9] and Hong et al. [38]. 
Table 7. Refinement results of oriented samples in AD and EG state.

\begin{tabular}{|c|c|c|c|c|c|c|c|c|}
\hline & \multirow[b]{2}{*}{ Start Value } & \multirow[b]{2}{*}{ Refinement Limits } & \multicolumn{2}{|c|}{ ISCz-1 (R1) } & \multicolumn{2}{|c|}{ 1M4 (R1) } & \multicolumn{2}{|c|}{ Ch4 (R1) } \\
\hline & & & $\begin{array}{c}\mathrm{AD} \\
R_{\mathrm{wp}}=8.85 \% \\
R_{\exp }=6.63 \%\end{array}$ & $\begin{array}{c}\mathrm{EG} \\
R_{\mathrm{wp}}=9.69 \% \\
R_{\exp }=6.69 \%\end{array}$ & $\begin{array}{c}\mathrm{AD} \\
R_{\mathrm{wp}}=7.66 \% \\
R_{\exp }=6.46 \%\end{array}$ & $\begin{array}{c}\mathrm{EG} \\
R_{\mathrm{wp}}=8.20 \% \\
R_{\exp }=6.60 \%\end{array}$ & $\begin{array}{c}\mathrm{AD} \\
R_{\mathrm{wp}}=8.67 \% \\
R_{\exp }=6.83 \%\end{array}$ & $\begin{array}{c}\text { EG } \\
R_{\mathrm{wp}}=10.47 \% \\
R_{\exp }=6.58 \%\end{array}$ \\
\hline \multicolumn{9}{|l|}{ Atomic occupancies } \\
\hline$p(\mathrm{~K})(3 \sigma)$ & 0.4 & $0.4-1$ & $0.66(9)$ & $0.61(2)$ & $0.51(9)$ & $0.75(7)$ & $0.50(5)$ & $0.68(8)$ \\
\hline$p(\mathrm{Ca})(3 \sigma)$ & 0.2 & $0.1-0.3$ & 0.1 & - & 0.3 & - & 0.1 & - \\
\hline$p(\mathrm{Fe})(3 \sigma)$ & 0.1 & $0-0.6$ & $0.065(2)$ & $0.062(2)$ & $0.070(2)$ & $0.18(3)$ & $0.05(1)$ & $0.069(3)$ \\
\hline \multicolumn{9}{|l|}{ Proportion and probabilities } \\
\hline & 0.5 & $0-1$ & $0.69(1)$ & $0.68(1)$ & $0.61(4)$ & $0.52(3)$ & $0.71(2)$ & $0.64(3)$ \\
\hline & & & \multicolumn{2}{|c|}{ Fuzz 6 (R3) } & \multicolumn{2}{|c|}{ JCC-1 (R3) } & \multicolumn{2}{|c|}{ ICz3 (R0) } \\
\hline & Start Value & Refinement Limits & $\begin{array}{c}\mathrm{AD} \\
R_{\mathrm{wp}}=7.25 \% \\
R_{\exp }=4.87 \%\end{array}$ & $\begin{array}{c}\mathrm{EG} \\
R_{\mathrm{wp}}=8.54 \% \\
R_{\exp }=5.22 \%\end{array}$ & $\begin{array}{c}\mathrm{AD} \\
R_{\mathrm{wp}}=10.75 \% \\
R_{\exp }=8.32 \%\end{array}$ & $\begin{array}{c}\mathrm{EG} \\
R_{\mathrm{wp}}=8.95 \% \\
R_{\exp }=7.98 \%\end{array}$ & $\begin{array}{c}\mathrm{AD} \\
R_{\mathrm{wp}}=7.06 \% \\
R_{\exp }=4.96 \%\end{array}$ & $\begin{array}{c}\text { EG } \\
R_{\mathrm{wp}}=8.50 \% \\
R_{\exp }=5.54 \%\end{array}$ \\
\hline \multicolumn{9}{|l|}{ Atomic occupancies } \\
\hline$p(\mathrm{~K})(3 \sigma)$ & 0.4 & $0.4-1$ & $0.74(3)$ & $0.57(5)$ & $0.60(3)$ & $0.67(5)$ & 0.4 & 0.4 \\
\hline$p(\mathrm{Ca})(3 \sigma)$ & 0.2 & $0.1-0.3$ & 0.3 & - & 0.1 & - & 0.17 & - \\
\hline $\begin{array}{l}\text { Proportion and probabilities } \\
\qquad w \mathrm{I}(3 \sigma)\end{array}$ & 0.5 & $0-1$ & $0.87(1)$ & $0.85(5)$ & $0.86(1)$ & $0.86(1)$ & $0.22(4)$ & $0.13(2)$ \\
\hline
\end{tabular}




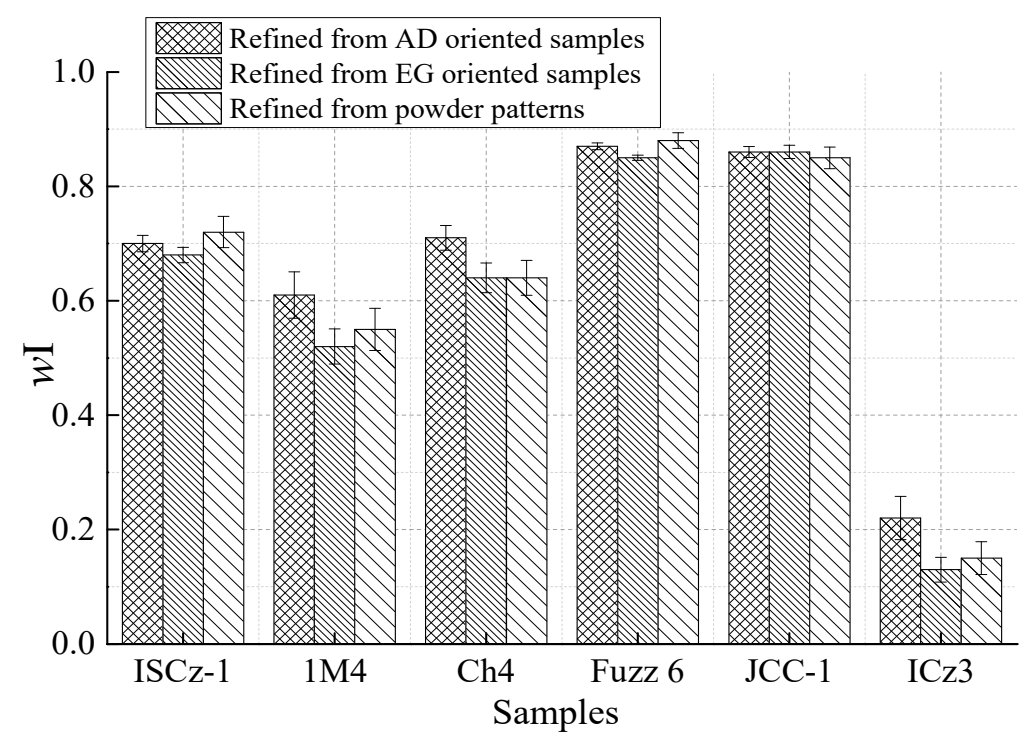

Figure 6. Refined values of proportion of illitic layers (wI) from AD, EG and powder samples.

Refined values of occupancies of potassium $p(\mathrm{~K})$ in AD state came close to the data determined by XRF analysis, except for sample ICz3 reached the refinement limits (Table 7, Figure 7). This may due to the high proportions of smectitic layers. The refined $p(\mathrm{~K})$ values of samples ISCz-1 and JCC-1 in EG state were closed to the expect data, but for other EG-intercalated samples were over- or under-estimated in comparison to chemical data. Sample ICz3 reached the refinement limits again (Figure 7). The similar conclusion of sample ISCz-1 was also found in the study of Ufer et al. [9].



Figure 7. Refined values of occupancy of potassium $p(\mathrm{~K})$, compared to the values obtained by the XRF analysis.

The refinement results for the occupancies of iron $p(\mathrm{Fe})$ of samples in the AD state were acceptable, only the sample $1 \mathrm{Cz} 3$ was strongly overestimated (Figure 8$)$. The refined $p(\mathrm{Fe})$ of EG-intercalated samples Ch4 and Fuzz6 were close to the experimental data, however, the refined values of EG samples ISCz-1, 1M4, JCC-1 and ICz3 were higher or strongly overestimated in comparison to the data determined by the XRF analysis (Figure 8). In the study of Ufer et al. [9], the refinement of iron content also showed unstable results. 




Figure 8. Refined values of occupancy of iron $p(\mathrm{Fe})$, compared to the values obtained by the XRF analysis.

The refined values of occupancies of the calcium $p(\mathrm{Ca})$ reached the refinement limits (Table 7). The same conclusion was reported by Ufer et al. [9]. The high correlation of interlayer cations with water molecule in the smectitic interlayer of I-S made the refinement of such parameters difficult.

\subsection{Rietveld Refinement on Powder Specimens}

The refinements of powder samples showed a good agreement between the measured and calculated patterns (Figure 9). The results were compared systematically with experimental data and also with the results of oriented specimens. The $R_{\mathrm{wp}}$ of refinements varied in the range of $4.44-6.59 \%$. Some Ca-saturated samples $(<0.2 \mu \mathrm{m})$ contained small amount of quartz (Table 8 ).
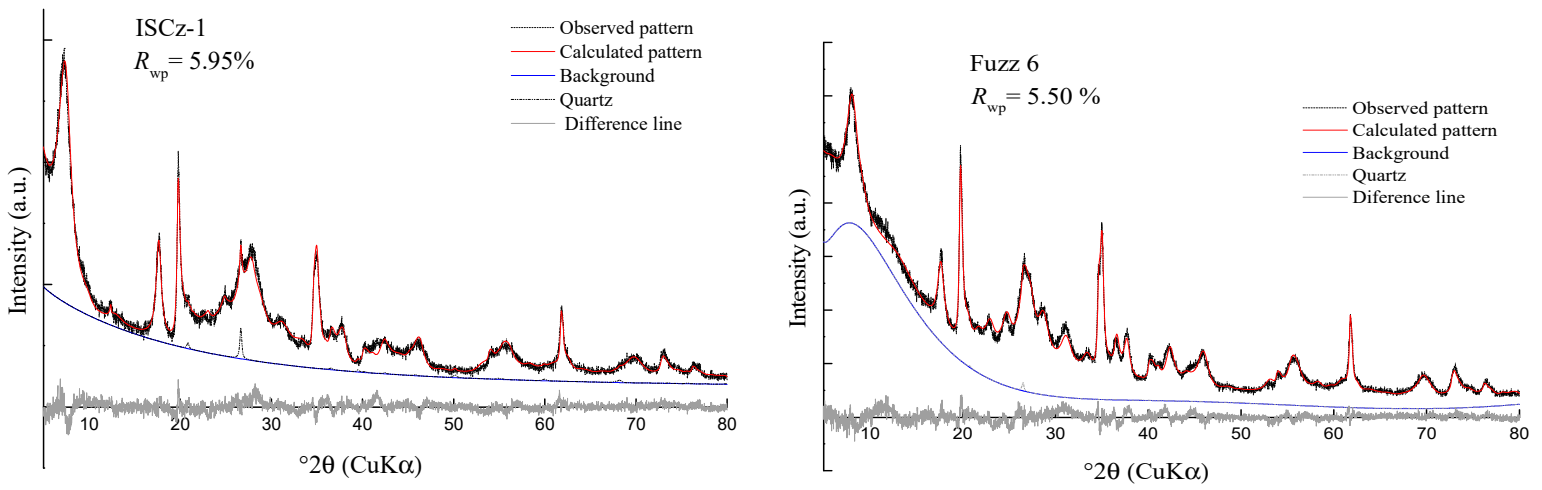

Figure 9. Rietveld refinements of powder diffraction patterns of samples ISCz-1 and Fuzz6.

The proportion of illitic layers $(w \mathrm{I})$ obtained from powder samples ranged from 0.15 to 0.88 (Table 8 ). By comparison, these refined $w$ I values were in good agreement with the values from oriented specimen in AD and EG state (Figure 6). It showed that the refinement of $w \mathrm{I}$ is reliable. The $w \mathrm{I}$ value of sample ISCz-1 0.72 was close to the reference value 0.7 from CMS and was larger than the value 0.6497 from the study of Ufer et al. [36]. The $w$ I value of sample Fuzz6 was $0.87(1)$ that was closed to the value 0.8745 of sample F4 obtained by Ufer et al. [36]. 
Table 8. Refinement results of powder samples.

\begin{tabular}{|c|c|c|c|c|c|c|c|c|}
\hline & \multirow{2}{*}{ Start Value } & \multirow{2}{*}{ Refinement Limits } & $\begin{array}{c}\text { ISCz-1 } \\
\text { R1 }\end{array}$ & $\begin{array}{c}\text { 1M4 } \\
\text { R1 }\end{array}$ & $\begin{array}{c}\text { Ch4 } \\
\text { R1 }\end{array}$ & $\begin{array}{c}\text { Fuzz6 } \\
\text { R3 }\end{array}$ & $\begin{array}{c}\text { JCC-1 } \\
\text { R3 }\end{array}$ & $\begin{array}{c}\text { ICz3 } \\
\text { R0 }\end{array}$ \\
\hline & & & $\begin{array}{l}R_{\mathrm{wp}}=5.95 \% \\
R_{\exp }=3.89 \%\end{array}$ & $\begin{array}{l}R_{\mathrm{wp}}=4.47 \% \\
R_{\exp }=3.22 \%\end{array}$ & $\begin{array}{l}R_{\mathrm{wp}}=4.61 \% \\
R_{\exp }=3.38 \%\end{array}$ & $\begin{array}{l}R_{\mathrm{wp}}=5.50 \% \\
R_{\exp }=3.60 \%\end{array}$ & $\begin{array}{l}R_{\mathrm{wp}}=4.44 \% \\
R_{\exp }=3.42 \%\end{array}$ & $\begin{array}{l}R_{\mathrm{wp}}=6.59 \% \\
R_{\exp }=3.06 \%\end{array}$ \\
\hline \multicolumn{9}{|l|}{ Contents [mass \%] } \\
\hline I-S $(3 \sigma)$ & & & $98.7(2)$ & 100.0 & $96.6(3)$ & $99.6(1)$ & $98.3(1)$ & 100.0 \\
\hline Quartz $(3 \sigma)$ & & & $1.3(2)$ & 0 & $3.4(3)$ & $0.4(1)$ & $1.7(1)$ & 0 \\
\hline \multicolumn{8}{|l|}{ Lattice parameter } & $0.5167(0)$ \\
\hline \multicolumn{9}{|l|}{ Atomic occupancies } \\
\hline$p(\mathrm{~K})(3 \sigma)$ & 0.4 & $0.4-1$ & $0.67(2)$ & $0.62(2)$ & $0.62(2)$ & $0.78(1)$ & $0.81(2)$ & 0.4 \\
\hline$p(\mathrm{Ca})(3 \sigma)$ & 0.2 & $0.01-0.3$ & 0.3 & 0.3 & 0.3 & 0.3 & 0.3 & 0.1 \\
\hline$p(\mathrm{Fe})(3 \sigma)$ & 0.2 & $0-0.7$ & $0.044(3)$ & $0.075(2)$ & $0.063(2)$ & 0 & $0.060(2)$ & 0 \\
\hline \multicolumn{9}{|c|}{ Proportion and probabilities } \\
\hline$w \mathrm{I}(3 \sigma)$ & 0.5 & $0-1$ & $0.72(3)$ & $0.55(4)$ & $0.64(3)$ & $0.88(1)$ & $0.85(2)$ & $0.15(3)$ \\
\hline $\mathrm{P} 0(3 \sigma)$ & 0.6 & $0.333-1$ & $0.49(12)$ & $0.39(3)$ & $0.33(2)$ & $0.64(9)$ & $0.69(9)$ & $0.49(9)$ \\
\hline $\mathrm{P} 60 / 120(3 \sigma)$ & 0.5 & $0-1$ & $0.49(2)$ & $0.55(4)$ & $0.51(5)$ & $0.44(2)$ & $0.47(2)$ & $0.54(5)$ \\
\hline $\operatorname{Pcv}(3 \sigma)$ & 0.5 & $0-1$ & $0.53(2)$ & $0.46(4)$ & $0.51(5)$ & $0.57(1)$ & $0.36(2)$ & $0.67(6)$ \\
\hline
\end{tabular}


The refinements of proportion of $c v$ layers (Pcv) led to satisfactory results (Figure 10). The refined values of Pcv were close to the experimental data which obtained by the thermal analysis, except to sample ICz3 was much lower than the experimental data. The proportion of $c v$ layers tended to decrease with increasing content of illitic layers $(w \mathrm{I})$ and potassium (Figure 11). The result is consistent with previous studies [14,22,24,45,46].

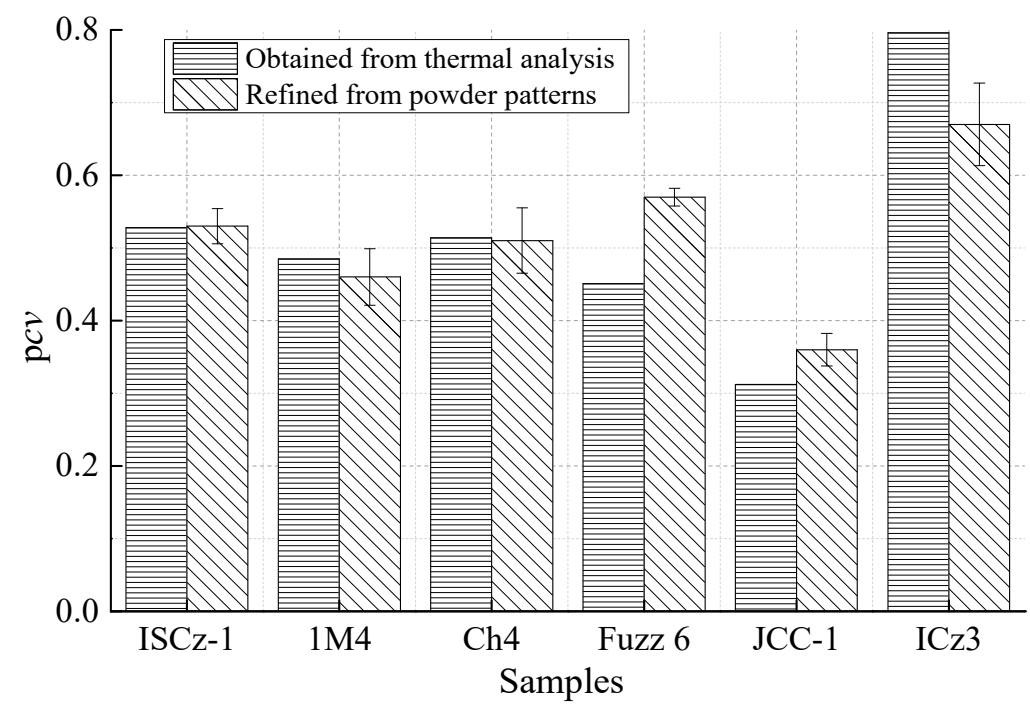

Figure 10. Refined values of probability of cis-vacant layers (Pcv), compared to the values obtained by the thermal analysis.

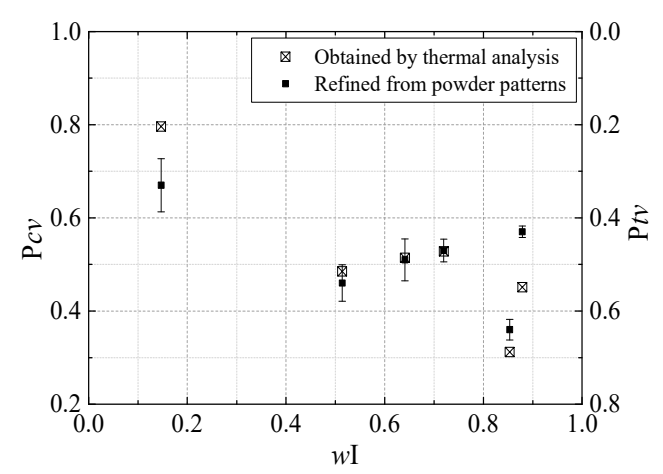

(a)

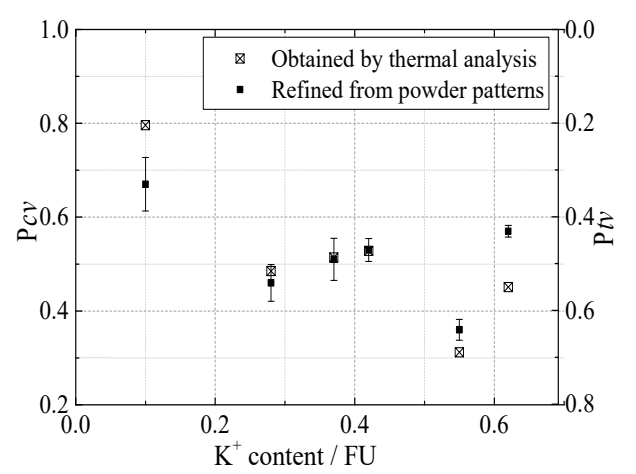

(b)

Figure 11. Relationship between the proportion of $c v$ and tv layers and (a) the proportion of illitic layers (wI); (b) the potassium content.

For most samples, the refined values of the occupancies $p(\mathrm{~K})$ from powder patterns were acceptable (Figure 7 ). For sample JCC-1 the refined $p(\mathrm{~K})$ was overestimated and sample ICz3 reached the refinement limits (Figure 11). The refined $p(\mathrm{~K})$ values of sample ISCz-1(0.67(2)) and Fuzz6 (0.78(1)) were close to the values (0.6638 and 0.7627) from Ufer et al. [36].

The occupancies of the octahedral iron $p(\mathrm{Fe})$ from powder patterns of samples ISCz-1, $1 \mathrm{M} 4, \mathrm{Ch} 4$ and JCC-1 led to satisfactory results, the refined values were in good agreement with the data obtained by XRF analysis (Figure 8). In contrast, the refinement on sample ISCz-1 showed unsatisfactory in the study of Ufer et al. [36]. It indicated the uncertainty of this structure method for this sample. The refined $p(\mathrm{Fe})$ value for sample Fuzz 6 was 0 , this result was acceptable because the occupancies of octahedral iron calculated from structural formula was 0.01 which was quite low (Table 4$)$. The refined $p(\mathrm{Fe})$ value of $1 \mathrm{Cz} 3$ reached the refinement limits. 
The refinement of occupancies $p(\mathrm{Ca})$ showed unsatisfactory results. The refined values of $p(\mathrm{Ca})$ were always reached the refinement limits, as the same in AD and EG state (Table 7). The results were consisting with the results from Ufer et al. [36]. The complex hydration behavior [47-49] and the high correlation of interlayer cations with water in the smectitic interlayer makes it more difficult to calculate $p(\mathrm{Ca})$ from XRD patterns. The refined values of probability and proportion parameters (p0, p60/120, p60 and p120) showed that most layers were not rotated for samples Fuzz6 and JCC-1 (p0 = 0.64 and 0.69, respectively); The ratio of $\mathrm{n} \cdot 60^{\circ}$ to $\mathrm{n} \cdot 120^{\circ}$ rotation (p60/120) was in the range of $0.44-0.55$ (Table 8). For sample ISCz-1 and Fuzz6, compared with the study of Ufer et al. [36], the refined values p0 were nearly identical.

\section{Conclusions}

The Rietveld refinements on oriented and powder samples showed that the calculated patterns were in good agreement with the measurement data. The refined $w$ I values derived from powder samples and oriented specimen in AD and EG state were comparatively consistent. The refinements of parameter Pcv led to satisfactory results and the results were in good agreement with the experimental data which obtained by the thermal analysis. The proportion of $c v$ layers decreased with the increasing content of potassium and iron, and the proportion of illitic layers. The refined values of $p(\mathrm{~K})$ and $p(\mathrm{Fe})$ from powder samples and oriented specimens in AD state were close to the data determined by XRF analysis. The refinements of $p(\mathrm{~K})$ and $p(\mathrm{Fe})$ from oriented specimens in EG state showed uncertain results. The values were over- or under-estimated in comparison to the experimental data. The refined $p(\mathrm{~K})$ value of sample ICz3 from AD, EG and powder patterns reached the lower refinement limits due to the high proportion of smectitic layers. The refinement of $p(\mathrm{Ca})$ was unsatisfactory for both oriented and powder samples. The refined values always reached the refinement limits. This structural parameter is highly correlated with the hydration states in the smectitic interlayer, which makes the refinement difficult. The refinement results of samples ISCz-1 and Fuzz6 were compared with the study of Ufer et al. $[9,36]$. The conclusions of these two studies were consistent.

The reliability of the refinement of structural parameters increased with increasing proportion of illitic layers. The powder patterns provided more reliable values for structural parameters of I-S samples. Because three-dimensional patterns contained more structure information than one-dimensional patterns. The evaluation of the refinements showed that the Rietveld method combined with a recursive structure-factor calculation has proven to be a suitable method for the determination of structural parameters of I-S and led to reasonable results.

Author Contributions: Conceptualization, X.W. and H.W.; Data curation, X.W.; Formal analysis, X.W. and H.W.; Funding acquisition, X.W. and H.W.; Investigation, X.W.; Project administration, X.W.; Supervision, H.W.; Writing—original draft, X.W.; Writing-review \& editing, X.W. and H.W. All authors have read and agreed to the published version of the manuscript.

Funding: This research was funded by the China Postdoctoral Science Foundation (grant number 2019M650320) and the National Natural Science Foundation of China (grant number 41872048).

Institutional Review Board Statement: Not applicable.

Informed Consent Statement: Not applicable.

Data Availability Statement: The data presented in this study are available on request from the corresponding author.

Acknowledgments: The authors greatly appreciate Reinhard Kleeberg (TU Bergakademie Freiberg) and Kristian Ufer (Federal Institute for Geosciences and Natural Resources) for their help in the refinement. The authors would like to thank Jan Środon and Hong Hanlie for providing the materials. The measurement of XRF were performed at the Analytical Instrumentation Center of Peking Universityand. The authors would like to thank Liu Jiahui for her help in the measurement.

Conflicts of Interest: The authors declare no conflict of interest. 


\section{References}

1. Drits, V.A.; Lindgreen, H.; Salyn, A.L. Determination by XRD of content and distribution of fixed ammonium in illite-smectite. Application to North Sea illite-smectite. Am. Mineral. 1997, 82, 80-88. [CrossRef]

2. Velde, B.; Köster, H.M.A. kinetic model of the smectite-to-illite trasformation based on diagenetic mineral series. Am. Mineral. 1992, 77, 967-976.

3. Śrondoń, J. Nature of mixed-layer clays and mechanisms of their formation and alteration. Annu. Rev. Earth Planet. Sci. 1999, 27, 19-53. [CrossRef]

4. Jagodzinski, H. Eindimensionale Fehlordnung in Kristallen und ihr Einfluss auf die Röntgeninterferenzen. I. Berechnung des Fehlordnungsgrades aus den Röntgenintensitäten. Acta Cryst. 1949, 2, 201-207. [CrossRef]

5. Reynolds, R.C.; Hower, J. The nature of interlayering in mixed-layer illite-montmorillonites. Clays Clay Miner. 1970, 18, 25-36. [CrossRef]

6. Reynolds, R.C. Interstratified Clay Minerals. In Crystal Structures of Clay Minerals and Their X-ray Identification, 2nd ed.; Brindley, G.W., Brown, G., Eds.; Mineralogical Society: London, UK, 1980; pp. 249-303.

7. Moore, D.M.; Reynolds, R.C. X-ray Diffraction and the Identification and Analysis of Clay Minerals, 2nd ed.; Oxford University Press: New York, NY, USA, 1997; pp. 335-339.

8. Nadeau, P.H.; Wilson, M.J.; McHardy, W.J.; Tait, J. Interstratified clays as fundamental particles. Science 1984, 225, 923-925. [CrossRef]

9. Ufer, K.; Kleeberg, R.; Bergmann, J.; Dohrmann, R. Rietveld refinement of disordered illitesmectite mixed-layer structures by a recursive algorithm. II: Powder pattern refinement and quantitative phase analysis. Clays Clay Miner. 2012, 60, 535-552. [CrossRef]

10. Biscoe, J.; Warren, B.E. An X-ray study of carbon black. J. Appl. Phys. 1942, 13, 364-371. [CrossRef]

11. Reynolds, R.C. X-ray diffraction studies of Illite-smectite from rocks, $<1 \mathrm{~mm}$ randomly oriented powders, and $<1 \mathrm{~mm}$ oriented powder aggregates: The absence of laboratory-induced artifacts. Clays Clay Miner. 1992, 40, 387-396.

12. Bish, D.L. Studies of clays and clay minerals using X-ray powder diffraction and the Rietveld method. In CMS Workshop, Computer Applications to X-ray Powder Diffraction Analysis of Clay Minerals; Walker, J.R., Reynolds, R.C., Eds.; Clay Minerals Society: Chantilly, VA, USA, 1993; Volume 5, pp. 79-112.

13. Tsipursky, S.I.; Drits, V.A. The distribution of octahedral cations in the 2:1 layers of dioctahedral smectites studied by obliquetexture electron diffraction. Clay Miner. 1984, 19, 177-193. [CrossRef]

14. Drits, V.A.; Lindgreen, H.; Salyn, A.L.; Ylagan, R.; McCarty, D.K. Semiquantitative determination of transvacantand cis-vacant 2:1 layers in illites and illite-smectites by thermal analysis and X-ray diffraction. Am. Mineral. 1998, 83, 1188-1198. [CrossRef]

15. Drits, V.A.; McCarty, D.K.; Zviagina, B.B. Crystalchemical factors responsible for the distribution of octahedral cations over transand cis-sites in dioctahedral 2:1 layer silicates. Clays Clay Miner. 2006, 54, 131-152. [CrossRef]

16. Drits, V.A.; Zviagina, B.B. Trans-vacant and cis-vacant 2:1 layer silicates: Structural features, identification, and occurrence. Clays Clay Miner. 2009, 57, 405-415. [CrossRef]

17. Méring, J.; Oberlin, A. Smectite. In The Electron Optical Investigation of Clays; Gard, J.A., Ed.; Mineralogical Society: London, UK, 1971; pp. 193-229.

18. Reynolds, R.C. Three dimensional X-ray powder diffraction from disordered illite: Simulation and interpretation of the diffraction patterns. In CMS Workshop, Computer Applications to X-ray Powder Diffraction Analysis of Clay Minerals; Walker, J.R., Reynolds, R.C., Eds.; Clay Minerals Society: Chantilly, VA, USA, 1993; Volume 5, pp. 43-78.

19. McCarty, D.K.; Reynolds, R.C. Rotationally disordered illite-smectite in Paleozoic K-bentonites. Clays Clay Miner. 1995, 43, 271-284. [CrossRef]

20. Drits, V.A.; Weber, F.; Salyn, A.L.; Tsipursky, S.L. X-ray identification of one-layer illite varieties: Application to the study of illites around uranium deposits of Canada. Clays Clay Miner. 1993, 41, 389-398. [CrossRef]

21. Drits, V.A.; Besson, G.; Muller, F. An improved model for structural transformations of heat-treated aluminous dioctahedral 2:1 layer silicates. Clays Clay Miner. 1995, 43, 718-731. [CrossRef]

22. Drits, V.A.; Salyn, A.L.; Šucha, V. Structural transformation of interstratified illite-smectites from Dolná Ves hydrothermal deposits: Dynamics and mechanisms. Clays Clay Miner. 1996, 44, 181-190. [CrossRef]

23. Drits, V.A. Structural and chemical heterogeneity of layer silicates and clay minerals. Clay Miner. 2003, 38, 403-432. [CrossRef]

24. Ylagan, R.F.; Altaner, S.P.; Pozzuoli, A. Reaction mechanisms of smectite illitization associated with hydrothermal alteration from Ponza island, Italy. Clays Clay Miner. 2000, 48, 610-631. [CrossRef]

25. Lindgreen, H.; Drits, V.A.; Sakharov, B.A.; Salyn, A.L.; Wrang, P.; Dainyak, L.G. Illite-smectite structural changes during metamorphism in black Cambrian Alum shales from the Baltic area. Am. Miner. 2000, 85, 1223-1238. [CrossRef]

26. Rietveld, H.M. Line profiles of neutron powder-diffraction peaks for structure refinement. Acta Cryst. 1967, 22, 151-152. [CrossRef]

27. Rietveld, H.M. A profile refinement method for nuclear and magnetic structures. J. Appl. Crystallogr. 1969, 2, 65-71. [CrossRef]

28. Aplin, A.C.; Matenaar, I.F.; McCarty, D.K.; van Der Pluijm, B.A. Influence of mechanical compaction and clay mineral diagenesis on the microfabric and porescale properties of deep-water gulf of Mexico mudstones. Clays Clay Miner. 2006, 54, 500-514. [CrossRef]

29. Yuan, H.; Bish, D.L. Automated fitting of X-ray powder diffraction patterns from interstratified phyllosilicates. Clays Clay Miner. 2010, 58, 727-742. [CrossRef] 
30. Reynolds, R.C. Wildfire: A Computer Program for the Calculation of Three-Dimensional Powder X-ray Diffraction Patterns for Mica Polytypes and their Disordered Variations; Hanover: New Hampshire, MA, USA, 1994.

31. Ufer, K.; Roth, G.; Kleeberg, R.; Stanjek, H.; Dohrmann, R.; Bergmann, J. Description of X-ray powder pattern of turbostratically disordered layer structures with a Rietveld compatible approach. Z. Kristallogr. 2004, 219, 519-527. [CrossRef]

32. Bergmann, J.; Friedel, P.; Kleeberg, R. BGMN-A new fundamental parameters based Rietveld program for laboratory X-ray sources; it's use in quantitative analysis and structure investigations. CPD Newsl. 1998, 20, 5-8.

33. Ufer, K.; Stanjek, H.; Roth, G.; Kleeberg, R.; Dohrmann, R.; Kaufhold, S. Quantitative phase analysis of bentonites by the Rietveld method. Clays Clay Miner. 2008, 56, 272-282. [CrossRef]

34. Wang, X.L.; Kleeberg, R.; Ufer, K. Routine investigation of important structural parameters of dioctahedral smectites by the Rietveld method. Appl. Clay Sci. 2018, 163, 257-264. [CrossRef]

35. Wang, X.L.; Liao, L.B. Rietveld structure refinement of Cu-trien exchanged nontronites. Front. Chem. 2018, 6, 558. [CrossRef] [PubMed]

36. Ufer, K.; Kleeberg, R.; Bergmann, J.; Dohrmann, R. Rietveld refinement of disordered illite-smectite mixed-layer structures by a recursive algorithm. I: One dimensional patterns. Clays Clay Miner. 2012, 60, 507-534. [CrossRef]

37. Środon, J.; Zeelmaekers, E.; Derkowski, A. Charge of component layers of illite-smectite in bentonites and the nature of end-member illite. Clays Clay Miner. 2009, 57, 649-671.

38. Hong, H.; Zhao, L.; Fang, Q.; Thomas, J.A.; Wang, C.; Yu, J.; Gong, N.; Yin, K.; Ji, K. Volcanic Sources and Diagenetic Alteration of Permian-triassic Boundary K-bentonites In Guizhou Province, South China. Palaeogeogr. Palaeoclimatol. Palaeoecol. 2019, 519, 141-153. [CrossRef]

39. Viczián, I. Hungarian investigations on the 'Zempleni' illite. Clays Clay Miner. 1997, 45, 114-115. [CrossRef]

40. Wang, X.L.; Li, Y.; Wang, H.J. Structural characterization of octahedral sheet in dioctahedral smectites by thermal analysis. Minerals 2020, 10, 347. [CrossRef]

41. Wolters, F.; Emmerich, K. Thermal reactions of smectites-Relation of dehydroxylation temperature to octahedral structure. Thermochim. Acta 2007, 462, 80-88. [CrossRef]

42. Klein, C. Elements of Crystal Chemistry. In Manual of Mineral Science, 22nd ed.; John Wiley and Sons Inc.: New York, NY, USA, 2008; pp. 38-103.

43. Wolters, F.; Lagaly, G.; Kahr, G.; Nüesch, R.; Emmerich, K. A comprehensive characterization of dioctahedral smectites. Clays Clay Miner. 2009, 57, 115-133. [CrossRef]

44. Köster, H.M.; Schwertmann, U. Dreischichtminerale; Tonminerale, T., Jasmund, K., Lagaly, G., Eds.; Steinkopff Verlag: Dresden, Germany, 1993; pp. 33-58.

45. Cuadros, J.; Altaner, S.P. Characterization of mixed-layer illite-smectite from bentonites using microscopic, chemical and X-ray methods: Constraints on the smectite-to-illite transformation mechanism. Am. Mineral. 1998, 83, 762-774. [CrossRef]

46. Cuadros, J.; Altaner, S.P. Compositional and structural features of the octahedral sheet in mixed-layer illite-smectite from bentonites. Eur. J. Mineral. 1998, 10, 111-124. [CrossRef]

47. Sato, T.; Watanabe, T.; Otsuka, R. Effects of layer charge, charge location, and energy change on expansion properties of dioctahedral smectites. Clays Clay Miner. 1992, 40, 103-113. [CrossRef]

48. Sato, T.; Murakami, T.; Watanabe, T. Change in layer charge of smectites and smectite layers in illite/smectite during diagenetic alteration. Clays Clay Miner. 1996, 44, 460-469. [CrossRef]

49. Ferrage, E.; Lanson, B.; Sakharov, B.A.; Drits, V.A. Investigation of smectite hydration properties by modeling experimental X-ray diffraction pattern. Part, I. Montmorillonite hydration properties. Am. Mineral. 2005, 90, 1358-1374. [CrossRef] 